\title{
Verbeter de zorg voor patiënten met beperkte gezondheidsvaardigheden: geleerde lessen uit de dagelijkse huisartsenpraktijk
}

\author{
Chantal Zuizewind · Jeroen Havers · Jeanny Engels · Karen Hosper · Hester van Bommel · Marieke Meppelder
}

Geaccepteerd op: 5 juli 2021 / Published online: 12 augustus 2021

(C) The Author(s) 2021

\section{Samenvatting}

Inleiding Gezondheidsvaardigheden ondersteunen het maken van weloverwogen keuzen met betrekking tot een gezonde leefstijl en het beter benutten van gezondheidszorg. Mensen met beperkte gezondheidsvaardigheden (BGV) vormen zodoende een groep in de samenleving die kwetsbaar is voor gezondheidsproblemen. In de huisartsenpraktijk kan nog veel gedaan worden om beter aan te sluiten op de vaardigheden van patiënten met $\mathrm{BGV}$ om te komen tot een betere gezondheid. Dit artikel reflecteert op de implementatie van een interventie die zorg beter moet afstemmen op mensen met BGV, in drie gezondheidscentra in achterstandswijken.

Methode Het betreft een inductieve thematische analyse van de ervaringen van de betrokken professionals, patiënten en externe adviseurs. Deze leverde een overzicht op van belemmerende en bevorderende factoren, en randvoorwaarden van de aanpak.

Resultaten Uit de analyses komen zes thema's naar voren die van belang zijn voor begeleiders van veranderprocessen als het gaat om het implementeren van goede ondersteuning aan patiënten met BGV in de huisartsenpraktijk: 1) het herkennen van BGV kost tijd, 2) een andere benadering van patiënten: reflectie

Digitaal aanvullende content De online versie van dit artikel (https://doi.org/10.1007/s12508-021-00312-z) bevat aanvullend materiaal, toegankelijk voor daartoe geautoriseerde gebruikers.

C. Zuizewind, MSc $\cdot$ J. Havers, MSc $\cdot$ J. Engels ·

Dr. M. Meppelder $(\square)$

Vilans, Landelijke kennisorganisatie voor de langdurende

zorg, Utrecht, Nederland

m.meppelder@vilans.nl

Dr. K. Hosper · H. van Bommel

Pharos, Expertisecentrum gezondheidsverschillen, Utrecht, Nederland op het eigen handelen, 3) samenwerken met patiënten, 4) structuur door projectleider en bijeenkomsten, 5) multidisciplinaire samenwerking, en 6) beweging op gang houden.

Conclusie Om betere zorg voor mensen met BGV te implementeren in de huisartsenzorg is aandacht voor het veranderproces nodig. De benodigde omslag bij professionals kost tijd en verloopt in kleine stapjes. Langdurige aandacht voor het onderwerp, in een multidisciplinaire setting, met goede procesbegeleiding én gelijkwaardige input van patiënten die zelf beperkt gezondheidsvaardig zijn, kunnen aan die omslag bijdragen.

Trefwoorden beperkte gezondheidsvaardigheden • huisarts · praktijkondersteuner huisarts . procesevaluatie

Improve care for patients with low health literacy skills: lessons learned in general practice

\begin{abstract}
Introduction Health literacy is an important determinant of healthy lifestyle and optimal use of health care and health advice. Therefore, people with lower health literacy skills are vulnerable to develop health problems. Primary care might be an influential surrounding to improve care for patients with low health literacy skills. This publication presents the findings of a three-year implementation project of a multidisciplinary approach to better support adults with low health literacy in three health centres for primary care. Method We induced conductive and inhibiting factors for implementation of the approach, based on a qualitative analysis of project data on experiences of professionals, patients and external advisors.

Results Qualitative analysis showed that factors influencing implementation of the approach can be di-
\end{abstract}


vided into six themes: 1) recognition of limited health literacy skills takes time, 2) knowledge, skills and tools to support patients: reflection on own approach, 3) patient participation, 4) a structured approach, 5) multidisciplinary cooperation and 6) sustainability. Conclusion To implement better care for patients with low health literacy skills in primary care, attention for the process of change is essential. Changing professionals' attitudes and behaviour takes time, and longitudinal dedicated attention for this process, with input from patients with low health literacy skills themselves, is necessary.

Keywords Low health literacy · General practitioner • Practice assistant GP · Process evaluation

\section{Inleiding}

In Nederland heeft maar liefst $29 \%$ van de volwassenen beperkte gezondheidsvaardigheden (BGV) [1]. Dit zijn 'de vaardigheden van mensen om informatie over gezondheid te verkrijgen, te begrijpen, te beoordelen en te gebruiken bij het nemen van gezondheidsgerelateerde beslissingen' [1]. Gezondheidsvaardigheden vormen de basis voor het maken van weloverwogen keuzen over leefstijl en het benutten van gezondheidsadviezen en gezondheidszorg. Mensen met BGV vormen zodoende een groep in de samenleving die kwetsbaar is voor gezondheidsproblemen [2].

Onderzoek toont aan dat mensen met BGV een slechtere gezondheid hebben [3, 4]. Ook maken ze meer gebruik van zorg [5], ervaren ze de kwaliteit van de zorg die ze krijgen als minder goed [6] en komen ze significant eerder te overlijden dan mensen met adequate gezondheidsvaardigheden [7].

Om gezondheidsachterstanden bij mensen met $\mathrm{BGV}$ te verminderen is het belangrijk om zorgprofessionals beter toe te rusten. Patiënten met BGV worden door zorgprofessionals nog te weinig, of pas veel later herkend, wanneer gezondheidsresultaten uitblijven doordat de ingezette informatiematerialen, zoals folders, niet geschikt blijken voor deze groep [8]. Als zorgprofessionals al op de hoogte zijn van de BGV van de patiënt, dan hebben ze vaak moeite om deze goed te ondersteunen, en om te komen tot betere gezondheid en zelfmanagement $[9,10]$. Ook maken zorgprofessionals nog nauwelijks gebruik van specifieke zelfmanagementtools voor deze groep [11].

Daarbij is het belangrijk om deze toerusting multidisciplinair en integraal uit te voeren $[12,13]$. Mensen met BGV ervaren problemen op verschillende gebieden, zoals arbeid, zorg, omgeving (fysiek en/of sociaal) en de ontwikkeling van persoonlijke vaardigheden. Als professionals van verschillende disciplines zich gezamenlijk toerusten op het gebied van BGV, en samen optrekken in het beter begeleiden van deze patiënten, kan hun gezondheid structureel verbeteren $[12,14]$.

Vilans (Kenniscentrum voor langdurige zorg) ontwikkelde met andere experts en professionals de Handreiking eerstelijns zorgverleners om zelfmanagement te ondersteunen bij mensen die beperkt gezondheidsvaardig zijn [15]. Deze bevat informatie om eerstelijnszorgprofessionals toe te rusten om BGV te herkennen en zorg beter op hen af te stemmen. Het doel van het huidige onderzoek is het ophalen en beschrijven van de geleerde lessen van de implementatie van deze handreiking in drie multidisciplinaire gezondheidscentra, zodat ook begeleiders van verandertrajecten in andere eerstelijnszorgcentra de handreiking succesvol kunnen implementeren.

\section{Methode}

\section{Doelgroep}

Drie gezondheidscentra uit achterstandswijken in Nederland namen deel aan dit project. Tabel 1 toont kenmerken van de drie gezondheidscentra.

\section{Interventie}

De interventie bestond uit het implementeren van de Handreiking eerstelijns zorgverleners om zelfmanagement te ondersteunen bij mensen die beperkt gezondheidsvaardig zijn [15]. Deze aanpak bestaat uit negen stappen om te komen tot het ontwikkelen, uitvoeren en evalueren van een teamplan voor zelfmanagementondersteuning van mensen met BGV (zie tab. 2).

De interventie werd uitgevoerd vanuit een projectgroep met zorgprofessionals uit de eerste lijn, onder wie een huisarts en praktijkondersteuner (ook projectleiders), een fysiotherapeut, een diëtiste, een apotheker, een praktijkondersteuner-ggz, een praktijkassistente en een apothekersassistente. Verder namen ook professionals uit het sociaal domein deel (een maatschappelijk werker uit buurt- of wijkteam), GGD of gemeente. Daarnaast namen tien patiënten deel aan de projectgroepbijeenkomsten: drie in gezondheids-

Tabel 1 Kenmerken van de deelnemende gezondheidscentra

\begin{tabular}{|l|l|l|l|}
\hline & gezondheidscentrum A & gezondheidscentrum B & gezondheidscentrum C \\
\hline provincie & Limburg & Gelderland & Utrecht \\
\hline aantal patiënten & 7.000 & 4.000 & 5.000 \\
\hline $\begin{array}{l}\text { disciplines verte- } \\
\text { genwoordigd in } \\
\text { gezondheidscen- } \\
\text { trum }\end{array}$ & $\begin{array}{l}\text { Huisarts, praktijkondersteuner/ } \\
\text { praktijkverpleegkundige, praktijkassistente, } \\
\text { fysiotherapeut, diëtist, apotheker, apothekersas- } \\
\text { sistente }\end{array}$ & $\begin{array}{l}\text { Huisarts, praktijkondersteuner/ } \\
\text { praktijkverpleegkundige, praktijkassistente, } \\
\text { fysiotherapeut, diëtist, apotheker, podothera- } \\
\text { peut }\end{array}$ & $\begin{array}{l}\text { Huisarts, praktijkondersteuner/ } \\
\text { praktijkverpleegkundige, praktijkassis- } \\
\text { tente, fysiotherapeut, diëtist, psycholoog }\end{array}$ \\
\hline
\end{tabular}


Tabel 2 Stappen om te komen tot een passende zelfmanagementondersteuning

\begin{tabular}{|l|l|}
\hline stap & activiteit \\
\hline 1 & $\begin{array}{l}\text { maken van een teamplan: probleemdefinitie, motivatie, teamvisie, com- } \\
\text { petenties, middelen, afspraken, taakverdeling, individueel zorgplan en } \\
\text { methoden/hulpmiddelen }\end{array}$ \\
\hline 2 & $\begin{array}{l}\text { herkennen van patiënten met BGV en een licht verstandelijke beperking } \\
\text { inrichten van de wachtkamer (beeld- en filmmateriaal beschikbaar) en } \\
\text { praktijkorganisatie (bewegwijzering en ophalen van de patiënt) }\end{array}$ \\
\hline 4 & $\begin{array}{l}\text { de patiënt maakt een afspraak voor een consult (aan de balie/telefoon): } \\
\text { benadruk dat tijdig hulp vragen altijd goed is, ondersteun bij vraagarticu- } \\
\text { latie en help de afspraak onthouden }\end{array}$ \\
\hline 5 & $\begin{array}{l}\text { de patiënt in de wachtkamer: de weg kunnen vinden, op zijn gemak } \\
\text { voelen en formulier kunnen invullen (indien nodig) }\end{array}$ \\
\hline 6 & $\begin{array}{l}\text { de patiënt voorbereiden op het consult en het bepalen van de agenda: } \\
\text { vraag de patiënt waarvoor hij het consult heeft aangevraagd, wat hij van } \\
\text { het consult verwacht en in elk geval wil weten }\end{array}$ \\
\hline 7 & $\begin{array}{l}\text { vaststellen van persoonlijk doel en actieplan: tips, suggesties en hulp- } \\
\text { middelen om dit samen met de patiënt te doen, ook bij vraagverlegen- } \\
\text { heid }\end{array}$ \\
\hline 8 & $\begin{array}{l}\text { organiseren van follow-up: doe dit flexibel en in overleg met de patiënt; } \\
\text { ga na hoe naasten of vrienden kunnen helpen }\end{array}$ \\
\hline 9 & $\begin{array}{l}\text { evaluatie met team en doelgroep (patiënten): lukt stimuleren van zelfma- } \\
\text { nagement, geleerde lessen en vraag enkele patiënten naar hun ervarin- } \\
\text { gen }\end{array}$ \\
\hline
\end{tabular}

centrum A, drie in gezondheidscentrum B en vier in gezondheidscentrum $\mathrm{C}$.

De projectgroep volgde de principes van cocreatie en design thinking en Participatory Learning and Action (PLA) om verschillende groepen (stakeholders) op een democratische en elkaar versterkende wijze samen te laten werken [16, 17]. De projectgroep kwam gedurende het project elf keer bij elkaar, waarbij de bijeenkomst werd vormgegeven via vooraf opgestelde werkbladen (zie S. 1, digitaal aanvullende content). De projectgroepen ontvingen ondersteuning van twee externe adviseurs van Vilans en Pharos.

\section{Dataverzameling en -analyse}

$\mathrm{Na}$ afloop van elke projectgroepbijeenkomst in de gezondheidscentra werd geëvalueerd met alle aanwezigen. De projectleiders en externe adviseurs zijn aan het einde van het project geïnterviewd. Uitwerkingen van deze evaluaties zijn met softwareprogramma MAXQDA versie 2018 inductief thematisch geanalyseerd door een onderzoeker (CZ) en werkstudent (RC). Na het onafhankelijk coderen van de eerste paar transcripten zijn de coderingen met elkaar vergeleken en verwerkt tot een definitieve thematisering op basis van consensus. Vervolgens zijn de overige transcripten op basis van deze thematisering gecodeerd.

\section{Resultaten}

Uit de analyses komen zes thema's naar voren die van belang zijn als het gaat om het organiseren van goede ondersteuning van patiënten met beperkte gezondheidsvaardigheden in de dagelijkse huisartsenpraktijk.

\section{Herkennen van BGV kost tijd}

Deelnemende professionals en externe adviseurs noemden het herkennen van mensen met BGV de meest essentiële en moeilijkste stap. Professionals realiseerden zich tijdens de bijeenkomsten steeds meer dat er veel patiënten in deze groep vallen, en gingen inzien wat zij te doen hadden om deze patiënten beter te ondersteunen. Een deelnemer van de projectgroep: 'We hoorden af en toe van: "Dit kan ik niet" of: "Dit wil ik niet." $\mathrm{Nu}$ pas begrijpen we dat dat echt zo is. Ze krijgen medicijnen en hebben geen idee wat ze moeten doen en ze durven dit niet te vragen. Jeetje, dit is zo belangrijk!'

Professionals noemden drie factoren die hebben bijgedragen aan het beter herkennen van BGV:

- een training over gezondheidsvaardigheden en effectief communiceren in de zorg;

- terugkerende aandacht tijdens de projectgroepbijeenkomsten voor het leren herkennen van signalen die kunnen wijzen op BGV;

- de inbreng en participatie van mensen met BGV tijdens de projectgroepbijeenkomsten; door de verhalen van patiënten hebben professionals het idee dat ze het hebben van BGV beter begrijpen.

\section{Een andere benadering van patiënten: reflectie op het eigen handelen}

Een essentieel onderdeel van de aanpak is dat professionals de juiste kennis en vaardigheden hebben om patiënten met BGV goed te kunnen ondersteunen. Gedurende het project realiseerden deelnemende professionals zich in kleine stapjes dat dit grote aanpassingen van hen ging vragen, niet alleen op gebieden waar ze dat misschien wel hadden verwacht, maar ook op gebieden waar ze dachten al op de goede weg te zijn of waar ze geen aanpassingen nodig achtten. Van communicatieve vaardigheden, zoals actief luisteren, eenvoudig, rustig en kort uitleg geven, kleine doelen stellen en patiënten terug laten vertellen wat ze gehoord hebben (terugvraagmethode), tot heel praktische zaken, zoals het gebruik van visuele materialen als plaatjes, filmpjes en anatomische modellen, het inplannen van een dubbel consult, patiënten vaker laten terugkomen, overzichtelijke praktijkinrichting of afspraken plannen op het hele uur. Een deelnemer van de projectgroep: 'Een patiënt zei tegen mij: "Als je me nu helpt om het ook iets gezelliger te hebben. Ik ben heel erg alleen. Ik heb zo veel problemen. Als ik meer moet gaan bewegen. Dan maar ergens waar het ook leuk is." Dit soort gesprekken maakt dat je aan andersoortige interventies gaat denken.'

\section{Samenwerken met patiënten}

Een belangrijke succesfactor in de aanpak van de gezondheidscentra is de deelname van patiënten aan de projectgroepbijeenkomsten. Professionals en ad- 
viseurs onderstrepen hoe belangrijk het is om uit de eerste hand te ervaren hoe het is om door het leven te gaan als je meer moeite hebt met lezen en schrijven of niet digitaal vaardig bent. Een adviseur: 'Je leert daar zo veel van. We zijn geneigd om snel dingen in te vullen. Terwijl situaties voor deze mensen heel anders kunnen lopen. De eerste twee bijeenkomsten hebben we deze mensen veel laten vertellen over hun ervaringen. Je hoort dan dingen waar je zelf nog nooit bij stil hebt gestaan.'

Het was voor de gezondheidscentra geen eenvoudige klus om patiënten bereid te krijgen deel te nemen aan het project. Een projectleider: 'Het aan tafel krijgen van drie laaggeletterde mensen, dat was ontzettend moeilijk. De meeste mensen hadden echt zoiets van: "Nou, echt niet. Ik durf het niet. Ik durf het echt niet."

Maar als patiënten meedoen, benadrukken ze de waarde van de samenwerking. Een deelnemer aan de projectgroep/patiënt: 'Ik vond het fijn om mee te doen. Het heeft mij ook geholpen. Dit heeft me een duwtje in de rug gegeven en daar wil ik jullie voor bedanken.'

Ondanks aanpassingen in de werkvormen (eenvoudige taal, meer tijd, kleine groepjes, visueel materiaal) gaven patiënten soms aan dat ze de gesprekken tijdens de bijeenkomsten niet goed kunnen volgen. Zorgprofessionals zeiden op hun beurt zoekend te zijn in de samenwerking met patiënten, bijvoorbeeld om het juiste taalgebruik in te schatten en aan te sluiten bij het tempo van patiënten. Een deelnemer aan de projectgroep: 'Er zijn natuurlijk ook momenten dat iemand helemaal van het onderwerp af gaat. Dat is dan maar eventjes zo. Ik denk als je iemand daar de ruimte niet voor geeft, dan krijg je ook geen bijdrage meer in de rest.'

\section{Structuur door projectleider en bijeenkomsten}

Het effectief ondersteunen van patiënten met BGV en alle facetten die daarbij komen kijken gaat niet van de ene op de andere dag. De gestructureerde aanpak om goede zelfmanagementondersteuning voor de patiënten op gang te krijgen én te houden werd gewaardeerd. Een deelnemer aan de projectgroep: 'Het bieden van structuur is heel belangrijk. Iedereen is bezig in de waan van de dag. Afspraken maken en taken verdelen helpt. Het vraagt misschien wat voorbereidingstijd, maar dan blijft iedereen ook betrokken.'

De gezondheidscentra vonden hun benodigde structuur en ritme met behulp van een aantal elementen. Allereerst door middel van het aanstellen van een interne projectleider, die gedurende het driejarig project als 'kartrekker' fungeerde en voor continuïteit en structurele agendering van het thema zorgde. Een deelnemer aan de projectgroep: 'De projectleider is de spin in het web geweest. Ik heb veel complimenten voor hoe zij dat heeft gedaan. Ik vertel mijn collega's bij de GGD hoe goed het hier nu gaat, mede door haar.'

Ook de steeds terugkerende projectgroepbijeenkomsten gaven structuur. Door bijeenkomsten op tijd in alle agenda's in te plannen en duidelijke afspraken te maken voor de tussentijdse perioden, vond men een goed houvast om het onderwerp BGV continu aandacht te geven.

\section{Multidisciplinaire samenwerking}

Het multidisciplinair implementeren van de handreiking en samen maken van een teamplan zijn volgens professionals essentieel voor het verbeteren van de zorg en ondersteuning bieden aan mensen met BGV. Professionals geven aan elkaar nodig te hebben: om de patiënten te signaleren, de juiste zorg te realiseren en indien nodig 'warm' over te dragen. Een deelnemer aan de projectgroep: 'Het is fijn om te weten dat, wanneer je je patiënt naar de diëtiste stuurt, ook zij op de hoogte is van de situatie met BGV [...] Dus ze zal het niet afdoen, van: "Die begrijpt er niets van." Ook daar wordt nu extra moeite gedaan.'

Om deze warme overdracht te realiseren is het belangrijk om collega's te laten weten dat een patiënt (mogelijk) BGV heeft. Dat laatste is nog niet altijd even eenvoudig. Patiënten schamen zich er soms voor omdat ze moeite hebben met lezen en schrijven, en of ze daar het open over kunnen spreken hangt af van hun relatie met de betrokken professional (vertrouwensband). Patiënten willen niet altijd dat hun zorgverlener deze informatie met anderen deelt. Een deelnemer aan de projectgroep/patiënt: 'Er moet vertrouwen zijn met de zorgverlener om te vertellen dat je moeite hebt met lezen en schrijven.'

Maar ook in gevallen waarbij de patiënt wel toestemming geeft voor de overdracht van zijn of haar BGV spelen er belemmeringen. Zo werken professionals van verschillende disciplines in verschillende digitale systemen die vaak niet met elkaar compatibel zijn. Daarnaast is er soms geen ruimte of code om laaggeletterdheid op te nemen in het dossier, of zijn professionals niet op de hoogte van de registratiemogelijkheden.

Naast een goede samenwerking binnen de gezondheidscentra bleek ook de samenwerking met het sociaal domein van groot belang. De problematiek waar mensen met BGV mee te maken hebben is vaak complex en doet zich op meerdere leefgebieden tegelijkertijd voor. Een projectleider: 'Omdat je in je eentje niet alles kunt oplossen. Ik heb echt het buurtteam nodig bij bepaalde zaken. En ik heb allerlei andere mensen eromheen nodig om te helpen bij de ondersteuning van iemand die dit soort problemen heeft.'

Professionals geven aan dat zij door het project meer verbinding hebben gezocht met lokale initiatieven en hierdoor beter op de hoogte zijn van de sociale kaart in de regio. Deze nauwere samenwerking bevordert bovendien het vinden van de juiste onder- 
steuning voor de patiënten. Een deelnemer aan de projectgroep: 'Mensen zijn nooit alleen maar laaggeletterd. Er spelen altijd andere zaken, bijvoorbeeld op sociaal of financieel vlak. Daarom is samenwerking zo belangrijk.'

Ook met het oog op de continuïteit van het aanbod is het belangrijk om samen te werken en verbindingen te leggen. Een deelnemer aan de projectgroep: 'Het zou voor onze patiënten veel makkelijker zijn als er drie of vier ondersteuningsgroepen per week waren. [...] Daarom willen we gaan verbinden met andere gezondheidscentra en initiatieven in de wijk. Als je meer volume hebt, kan je beter en flexibeler aanbieden.'

Het bleek lastig om een grote diversiteit aan professionals bij het project te betrekken en betrokken te houden. Tijdens het project wisselde een aantal afgevaardigden van de organisaties van baan, waardoor de betrokkenheid van deze organisaties (tijdelijk) afnam. Daarnaast was het voor elk van de disciplines ingewikkeld om de eigen achterban te bereiken en te motiveren. Als professionals tijdens de projectgroepbijeenkomsten meer leerden over BGV, wilde dat nog niet zeggen dat ze dat op hun collega's konden overbrengen.

\section{Beweging op gang houden}

$\mathrm{Na}$ een periode van drie jaar samenwerken gaan de gezondheidscentra nu buiten de kaders van het projectverband hun ambitie verder vormgeven. De gezondheidscentra staan nu voor de belangrijke uitdaging om de beweging die op gang is gekomen structureel te borgen. Een projectleider: 'Nu hebben we een structuur dankzij het project. Als die wegvalt, dan wordt het natuurlijk toch lastig om het in leven te houden.'

Aandacht blijven houden voor het thema gezondheidsvaardigheden is niet makkelijk. Zeker binnen een context waar een hoge werkdruk, personeelswisselingen, gebrek aan financiële middelen en tijd aan de orde van de dag zijn. Een deelnemer aan de projectgroep: 'De grootste belemmering zit 'm natuurlijk gewoon in mezelf. Bij alle zorgverleners geldt dat het natuurlijk een onderwerp is in een hele reeks waar je mee bezig bent. Terwijl je natuurlijk eigenlijk geleefd wordt door hoe de hele dag op je af komt.'

Volgens professionals is een blijvende inzet op gedeelde verantwoordelijkheid nodig. Een projectleider: 'Volgende week hebben we de laatste bijeenkomst. Daar krijgen de mensen ook wat huiswerk voor deze week, om na te denken hoe ze het vervolg vorm willen geven. Het idee is dat we iedereen een eigen stukje geven waar ze verantwoordelijk voor worden. Zodat het niet bij één persoon komt te liggen. (...) Dat zal heel belangrijk zijn om het te borgen.'

Ook voor het bereiken en beïnvloeden van de patiënten is continue aandacht voor het onderwerp belangrijk. Projectleider: 'Je hebt van die patiënten waar je de klik niet mee hebt. Dat je denkt, ik ben nu iets aan het vertellen over voeding, maar het komt gewoon niet binnen. Het lijkt net of je op een muurtje stuit. $\mathrm{Nu}$ denk ik dan, ik ga dat consult heel anders doen. Dan hebben we het maar een keer helemaal niet over die suiker. En ja, dan hoor ik dus ook heel andere dingen.'

Stap voor stap, patiënt voor patiënt, lijkt het motto waar de gezondheidscentra zich nu aan vasthouden.

\section{Beschouwing en conclusie}

In dit artikel reflecteren we op een meerjarig implementatietraject in drie gezondheidscentra om professionals te ondersteunen bij het beter afstemmen van hun zorg op volwassenen met BGV. Met de resultaten van dit project kaarten we zes thema's aan, die van belang zijn bij de implementatie van de Handreiking eerstelijns zorgverleners om zelfmanagement te ondersteunen bij mensen die beperkt gezondheidsvaardig zijn [15]: 1) het herkennen van BGV kost tijd, 2) een andere benadering van patiënten: reflectie op het eigen handelen, 3) samenwerken met patiënten, 4) structuur door projectleider en bijeenkomsten, 5) multidisciplinaire samenwerking, en 6) beweging op gang houden.

De resultaten laten zien dat implementatie van betere zorg voor mensen met BGV vraagt om een combinatie van inhoudelijke kennis en een passende veranderkundige aanpak.

Een cruciaal onderdeel van de implementatie was de samenwerking met patiënten in de projectgroepen. Hoewel de inzet en kracht van ervaringsdeskundigheid in diverse vakgebieden in opkomst is [18], is een gelijkwaardige samenwerking met patiënten zeker vernieuwend te noemen. Professionals en patiënten ervaarden de samenwerking als prettig en leerzaam, en dachten dat deze een positief effect op de uitkomsten van het project had. Deze bevindingen sluiten aan bij ander onderzoek naar het gelijkwaardig betrekken van alle belanghebbenden, dus ook patiënten, bij het onderzoeken en verbeteren van eerstelijnszorg. Een dergelijke aanpak kan leiden tot persoonlijke voordelen (zoals een verhoogd gevoel van empowerment of eigenwaarde), een toename van kennis en een verbetering van vaardigheden [19].

Ook het samenwerken met andere disciplines werd bij de implementatie als een bevorderende factor ervaren. Tegelijk vormde het interdisciplinaire karakter van het project een van de grootste uitdagingen. Mogelijk had het geholpen om voorafgaand aan het project meer te investeren in het vormen van een draagvlak bij de verschillende disciplines, om een gezamenlijk verantwoordelijkheidsgevoel te creëren. Diverse organisaties hadden moeite om de achterban te bereiken. Meer ondersteuning daarbij vanuit het project had kunnen helpen om ook bij deze professionals een groter verschil te maken. Daarnaast kan de diversiteit aan gebruikte systemen de samenwerking tus- 
sen de verschillende disciplines belemmeren. Hierdoor is continuïteit in het registreren van BGV, en de overdracht daarvan, lastig te handhaven. Bij volgende projecten waarbij professionals worden ondersteund bij het beter afstemmen van hun zorg op volwassenen met $\mathrm{BGV}$ is het raadzaam om ook te zoeken naar oplossingen om BGV beter te registeren en de communicatie hierover tussen de systemen te verbeteren.

De resultaten van het huidige onderzoek zijn verwerkt in een nieuwe versie van de handreiking [20]. Deze handreiking is afgestemd op professionals die in hun werksituatie een verandertraject willen opstarten om tot betere zorg voor mensen met BGV te komen. Ze hebben niet alleen behoefte aan veel inhoudelijke informatie over BGV, maar ook aan concrete handvatten om samen met andere disciplines een traject te kunnen opstarten. Dat gebeurt onder andere in het hoofdstuk 'Voordat je begint', met aandacht voor de randvoorwaarden van een verandertraject, en de paragraaf 'De projectgroepbijeenkomsten', waarin de betrokkenheid van patiënten wordt toegelicht. Met deze combinatie van inhoudelijke kennis en veranderkundige handvatten wordt de kans groter dat professionals hun zorg beter kunnen afstemmen op patiënten met BGV.

Meer informatie en voorbeelden zijn te vinden in het artikel 'Eindelijk kan ik hen iets bieden' in De Eerstelijns van april 2019 en 'Pilot levert nuttige inzicht op' in De POH van september 2019 [21, 22].

Dankbetuiging Dank gaat uit naar de gezondheidscentra en de projectteams voor hun bijdrage aan het project. We danken Romée Casteleijn voor haar bijdrage aan het coderen van de onderzoeksdata.

Open Access This article is licensed under a Creative Commons Attribution 4.0 International License, which permits use, sharing, adaptation, distribution and reproduction in any medium or format, as long as you give appropriate credit to the original author(s) and the source, provide a link to the Creative Commons licence, and indicate if changes were made. The images or other third party material in this article are included in the article's Creative Commons licence, unless indicated otherwise in a credit line to the material. If material is not included in the article's Creative Commons licence and your intended use is not permitted by statutory regulation or exceeds the permitted use, you will need to obtain permission directly from the copyright holder. To view a copy of this licence, visit http://creativecommons.org/licenses/by/4.0/.

\section{Literatuur}

1. Heijmans M, Brabers A, Rademakers J. Hoe gezondheidsvaardig is Nederland? Factsheet Gezondheidsvaardigheden-Cijfers 2019. Utrecht: Nivel; 2019.

2. Rademakers J. Gezondheidsvaardigheden. Niet voor iedereen vanzelfsprekend. Utrecht: Nivel; 2014.

3. Hoeymans N, Melse JM, Schoemaker CG. Gezondheid en determinanten. Deelrapport van de VTV 210 Van gezond naar beter. Bilthoven: RIVM; 2010.
4. Heide I van der, Uiters E, Rademakers J, Struijs JN, Schuit AJ, Baan CA. Associations among health literacy, diabetes knowledge, and self-management behavior in adults with diabetes: results of a Dutch cross-sectional study. J Health Commun. 2014;19(suppl2):115-31.

5. Groot WNJ, Maassen van den Brink HM. Stil vermogen: een onderzoek naar de maatschappelijke kosten van laaggeletterdheid. Den Haag: Stichting Lezen en Schrijven; 2006.

6. Berkman ND, Sheridan SL, Donahue KE, Halpern DJ, Crotty K. Lowhealthliteracy and health outcomes: an updated systematic review. Ann Intern Med. 2011;155(2):97-107.

7. Bostock S, Steptoe A. Association between low functional health literacy and mortality in older adults: longitudinal cohortstudy. BMJ. 2012;344:1602.

8. Ee A van. Patients with low literacy in primary care in the Netherlands: need to support the general practitioner? Nijmegen: Radboud UMC;2014.

9. Wijenberg E, Engels J. Mensen met beperkte gezondheidsvaardigheden zijn beter te helpen. Resultaten van interviews metzorgverleners en experts. Praktijk. 2013;4:11-3.

10. Feia H. Onbekend maakt onbemind: huisarts en allochtone patiënt. Utrecht: UMC Utrecht/Pharos; 2010.

11. WijenbergE, Engels J, Bommel Hvan. Mensen metbeperkte gezondheidsvaardigheden. Geen doorsnee patiënt. $\mathrm{POH}$. 2015;2:34-6.

12. Beenackers MA, Nusselder WJ, Oude Groeniger J, Lenthe FJ van. Het terugdringen van gezondheidsachterstanden: een systematisch overzicht van kansrijke en effectieve interventies. Rotterdam: Erasmus MC Universitair Medisch Centrum;2016.

13. Haker F, Hosper K, Loenen T. Gezondheidsverschillen duurzaam aanpakken. De negen principes voor een succesvolle strategie. Utrecht: Pharos; 2019.

14. Kickbusch I, Pelikan JM, ApfelF, Tsouros AD. Health literacy. The solid facts. Geneva: World Health Organisation; 2013.

15. Engels J, Wijenberg E, Schepers B. Zelfmanagement en beperkte gezondheidsvaardigheden. Handreiking eerstelijns zorgverleners om zelfmanagement te ondersteunen bij mensen die beperkt gezondheidsvaardig zijn. Utrecht: Vilans; 2014.

16. Steen M. Co-design as a process of joint inquiry and imagination. Des Issues. 2013;29(2):16-28.

17. Aldridge J. Participatory research: working with vulnerable groups in research and practice. Bristol: Policy Press; 2016.

18. Aldridge J. Working with vulnerable groups in social research: dilemmas by default and design. Qual Res. 2014;14(1):112-30.

19. BrettJ, Staniszewska S, Mockford C, Seers K, Herron-Marx S, Bayliss H. The PIRICOM study: a systematic review of the conceptualization, measurement, impact and outcomes of patients' and public involvement in health and social care research. London: Royal College of Nursing Research Institute; 2010.

20. Engels J, Havers J. Handreiking aandacht voor zelfmanagement én gezondheidsvaardigheden. Utrecht: Vilans; 2019 .

21. Engels J, Hosper K, Bommel H van. Eindelijk kan ik hen iets bieden. Eerstelijns. 2019. pag. 40-2.

22. Engels J, Havers J, Smallegange A. Pilot levert nuttige inzicht op. Zelfmanagement en gezondheidsvaardigheden. $\mathrm{POH}$. 2019;9:6-9. 